\title{
Trabalho e Saúde em Motoristas de Caminhão no Interior de São Paulo
}

Work and Health of Truck Drivers in the State of São Paulo

\author{
Regina Zanella Penteado \\ Fonoaudióloga. Especialista em Linguagem e em Voz. Doutora \\ em Saúde Pública. Professora do Curso de Fonoaudiologia da \\ Universidade Metodista de Piracicaba (Unimep). \\ Endereço: Avenida 41, n. 209, apto 62, CEP 13501-190 Rio Claro, \\ SP, Brasil. \\ E-mail: rzpenteadoळunimep.br

\section{Claudia Giglio de Oliveira Gonçalves} \\ Fonoaudióloga, Especialista em Ergonomia. Doutora em Saúde \\ Coletiva. Professora da Universidade Tuiuti do Paraná. \\ Endereço: Rua Sydnei Antonio Rangel Santos, 238, CEP 82020-330, \\ Curitiba, PR, Brasil. \\ E-mail: clgiglio@terra.com.br

\section{Daniele Damaris da Costa} \\ Fonoaudióloga. \\ Endereço: Rua José Valentin Casati n. 492. CEP 13477030, Ameri- \\ cana, SP, Brasil. \\ E-mail: danieledamarisळyahoo.com.br

\section{Jair Mendes Marques} \\ Matemático. Doutor em Ciências Geodésicas. Professor da Univer- \\ sidade Tuiuti do Paraná. \\ Endereço: Rua Sydnei Antonio Rangel Santos n. 238, CEP 82020- \\ 330, Curitiba, PR, Brasil. \\ E-mail: jair.marquesळutp.br
}

\section{Resumo}

O objetivo desta pesquisa é analisar alguns aspectos de saúde e de trabalho de caminhoneiros, identificando possíveis relações, determinantes e/ou agravantes, de impactos negativos na sua qualidade de vida. Método: foram entrevistados 400 caminhoneiros do interior de São Paulo, na Rodovia SP-33o. Utilizou-se um questionário fechado, que aborda aspectos da percepção dos motoristas sobre a sua saúde e trabalho. Resultados: $59,5 \%$ dos trabalhadores são autônomos e 58,5\% viajam em rota curta (no limite do Estado), trabalham em média 12,7 horas diárias e tem entre 5 a 8 horas de sono. Referiram problemas constantes ou ocasionais de postura $(67,75 \%)$, auditivos $(37,75 \%)$, estomacais $(57,5 \%)$, resfriados/gripes (70\%), sentimentos negativos como medo, estresse e depressão $(58,5 \%)$, tonturas ( $23 \%$ ), rouquidão (30,75\%), pigarro (36,5\%), tosse (53,5\%). Quanto aos hábitos de consumo e comportamentos, ingerem café $(87,75 \%)$, alimentos gordurosos $(84,5 \%)$, bebidas alcoólicas (43\%), energéticos (19,5\%); fumam (32\%) e usam outras drogas (2\%). Conclusão: Diversos aspectos das condições de trabalho, hábitos e comportamentos de motoristas de caminhão exercem impactos negativos sobre sua saúde, com prejuízos para a comunicação e a qualidade de vida.

Palavras-chave: Promoção da saúde; Qualidade de vida; Trabalho; Saúde ocupacional. 


\section{Abstract}

The aim of the present study is to assess some aspects of health and work of truck drivers and to identify possible relationships, determining and/or aggravating factors of negative impacts in their quality of life. Method: 400 truck drivers in a city of SP in SP330 Highway were interviewed. A closed questionnaire was used approaching aspects of the drivers' perception of their health and work. Results: $59.5 \%$ of workers are self-employed, and $58.5 \%$ do only short travels (within the limits of the State), they work an average 12.7 hours/day and have from 5-8 hours of sleep. Regarding health, they reported constant or occasional postural $(67.75 \%)$, auditory $(37.75 \%)$, and stomach problems $(57.5 \%)$ as well as colds (70\%), negative feelings such as fear, stress and depression (58.5\%), dizziness (23\%), hoarseness (30.75\%), hem (36.5\%), cough (53.5\%). Regarding consumption habits and behaviors, $87.75 \%$ drank coffee, $84.5 \%$ ate greasy food, $43 \%$ had alcoholic beverages, $19.5 \%$ used energizers, 32\% smoked, and $2 \%$ used other drugs. Conclusion: Several aspects of working conditions, habits and behaviors of truck drivers have negative impacts on health, impairing communication and quality of life.

Keywords: Health Promotion; Quality of Life; Work; Occupational Health.

\section{Introdução}

Os motoristas profissionais, tanto de transporte coletivo quanto de transporte de cargas, sofrem comprometimentos na saúde em decorrência do exercício da sua atividade profissional.

Diversas pesquisas vêm descrevendo os comprometimentos da saúde nessa categoria profissional.

Problemas como a perda auditiva induzida por ruído (PAIR), hipertensão, estresse, câncer, doenças do sono, refluxo gastroesofágico, doenças cardiovasculares e do músculo-esquelético, além do envolvimento em acidentes de trânsito são comumente descritos na literatura (Cordeiro e col., 1994; Corrêa Filho e col., 2002; Montovani e Weber, 2002; Cepinho e col., 2003; Freitas e Nakamura, 2003; Mendes, 2003; Silva e Mendes, 2005).

Entre os motoristas profissionais, o risco de adoecer é aumentado por causa de determinadas situações - é o caso das doenças cardiovasculares e músculo-esqueléticas, que variam em função da idade e dos anos de escolaridade dos motoristas, com risco aumentado para os trabalhadores dos setores de cargas e de passageiros (Neri Soares e Soares, 2005). Na Dinamarca, em um estudo envolvendo 2.465 motoristas de ônibus, entre 1978 e 1985, os autores Netterstrom e Juel (1988) encontraram um aumento no risco de infarto do miocárdio devido às condições de trabalho dos motoristas, como a alta carga de trabalho, o tráfego intenso, nenhum contato com os colegas e o hábito de fumar.

0 excesso de atividade de trabalho na categoria dos motoristas também é considerado risco para doenças como os distúrbios do sono, varizes, hérnia de disco e hemorróidas, em função da intensa jornada de trabalho (Mello e col., 200o).

Essa diversidade de agravos da saúde dos motoristas profissionais tem um impacto negativo na sua qualidade de vida, entendida como um conceito amplo que abrange a complexidade de um construto social, cultural, subjetivo e multidimensional, composto de elementos de avaliação tanto positivos quanto negativos e perpassada pela linguagem e comunicação (Fleck, 1999; Fleck e col., 2000; Ramírez, 2001).

Para ser saudável, o sujeito precisa estar bem física, emocional e socialmente, portanto, integrado ao seu meio social, o que implica poder comunicar-se satisfatoriamente também (Oliveira, 1998). A saúde e a qualidade de vida estão, assim, relacionadas à comunicação. 
Nesse sentido, vale destacar a importância da linguagem oral, que envolve o uso da voz e da fala, para a relação interpessoal, presente nos processos de socialização humana e produzindo impactos na qualidade de vida dos sujeitos. Problemas dessa natureza podem ter implicações na autoimagem, nos relacionamentos sociais e afetivos, nas necessidades comunicativas diárias, nas opções de lazer, nos projetos pessoais e no exercício da profissão, de maneira que a comunicação deve ser pensada em relação à saúde geral e à qualidade de vida das pessoas, considerando-se as condições e organização do trabalho (Penteado, 2004, 2006; Gonçalves e col., 2005).

Segundo o Ministério do Trabalho e Emprego, motoristas de caminhão são trabalhadores autônomos ou assalariados que, prestando serviços para empresas pertencentes aos ramos de logística e transporte terrestre, transportam, coletam, guincham, destombam, removem e entregam cargas em geral, dentre outras funções. Dentro da sua área de atuação ainda se encontra a atividade de comunicar-se (informar a saída, a chegada, os desvios de rota, etc.), em tempo real (através de telefone, rádio-amador ou via satélite), fazendo parte de seus recursos de trabalho também os aparelhos de comunicação instalados no veículo (Brasil, 2005). Assim, a qualidade do trabalho de um motorista profissional pode ficar comprometida se a capacidade de se comunicar adequadamente for prejudicada em função das condições e dos riscos presentes no seu trabalho ou mesmo dos hábitos e comportamentos que têm implicações na saúde geral e vocal.

Estudos fonoaudiológicos (Miranda e col., 2005; Penteado e col., 2005; Costa e col., 2005) realizados com motoristas de caminhão identificaram a presença de queixas e sintomas vocais e interferências na comunicação, tais como: rouquidão, pigarro, tosse, afonia, garganta seca, dor/ardor na garganta, falta de ar, desconforto, cansaço, falhas ou quebras na voz ao falar e ao cantar. As autoras indicam como possíveis aspectos intervenientes e agravantes desses problemas os hábitos vocais de gritar, cantar e falar muito e alto; as condições ambientais como poeira, fumaça, fuligem de queimada, cheiros fortes e produtos químicos, vento, friagem ou mudança de temperatura, além de hábitos alimentares inadequados e consumo de álcool, fumo e drogas.
Na área da Saúde do Trabalhador, busca-se transformar os processos de trabalho nos seus diversos aspectos, eliminando os riscos e buscando formas de inserção dos trabalhadores no seu trabalho que propiciem a saúde e a qualidade de vida (Alves, 2003). Neste enfoque, a interdisciplinaridade é necessária, pois a Saúde do Trabalhador é um campo estruturado por diversas áreas de conhecimento.

O objetivo desta pesquisa é analisar alguns aspectos da saúde e das condições de trabalho de motoristas de caminhão do interior de São Paulo, buscando identificar possíveis relações e determinantes e/ou agravantes de impactos negativos na sua qualidade de vida.

\section{Material e Método}

A pesquisa envolveu a aplicação de questionário tipo fechado/múltipla escolha, abordando alguns aspectos de saúde geral e de condições de trabalho de motoristas de caminhão (Anexo). o questionário abordou, ainda, outras questões específicas relacionadas à saúde vocal, que não se fazem parte deste estudo, mas que irão constituir estudos futuros.

A coleta de dados foi realizada no período de janeiro a julho de 2005. Os questionários foram aplicados em caminhoneiros, durante o período diurno, em locais de paradas, como estacionamentos de carga/descarga e postos de abastecimento de combustível da Rodovia SP-33o (no interior do Estado de São Paulo, especialmente na região de Americana e Piracicaba). Vale ressaltar que os sujeitos não foram submetidos a consultas ou exames clínicos e as respostas referentes a problemas de saúde ou queixas não decorrem de avaliação médica, são oriundas das percepções dos próprios caminhoneiros.

Participaram da pesquisa 400 motoristas de caminhão do sexo masculino, com idade entre 21 e 65 anos.

Os dados receberam tratamento estatístico por meio de análise descritiva e analítica:

1. Análise descritiva: cálculo de médias e desvios padrões das variáveis (idade, horas de trabalho).

2. Testes não-paramétricos: Qui-Quadrado, para verificação da associação entre as variáveis (idade, horas de trabalho, horas de sono, queixas e problemas de saúde, hábitos de consumo e comportamento), ao nível de significância de $5 \%(\mathrm{p}<0,05)$. 
A pesquisa que originou este estudo obteve aprovação no Comitê de Ética em Pesquisa da Unimep (19/05 de 5/05/2005).

\section{Resultados}

Os motoristas entrevistados trabalham como autônomos $(59,5 \%)$ ou empregados (40,5\%), efetuando rota do tipo curta $(58,5 \%)$, ou seja, no limite do Estado; longa $(37,2 \%)$, ou seja, interestadual ou internacional e alternada curta/longa (4,2\%). Transportavam carga do tipo: seca (59,5\%), constituída por produtos como máquinas, “container”, madeiras, materiais de construção, mudanças, plásticos, dentre outros; viva (3\%), como bovinos e aves; química (20,5\%), constituída por materiais como cimento, gases, corrosivos, inflamáveis, materiais tóxicos, dentre outros; resfriada (o,5\%), para frigoríficos; alimentícia (14,5\%), água, grãos, frutas e outros produtos industrializados. Possuíam os seguintes modelos de caminhão: baú, carroceria, convencional e sider.

A idade média dos motoristas estudados (40o) foi de 42,2 anos (desvio padrão de 10,4):

\section{Tabela I - Número e proporção dos motoristas estudados por faixas etárias, São Paulo, 2005 ( $\mathrm{N}=400)$}

\begin{tabular}{l|c|c}
\hline Faixa etária (anos) & $\mathrm{N}$ & $\%$ \\
\hline Até 29 & 57 & 14 \\
\hline 30 a 39 & 86 & 21 \\
\hline 40 a 49 & 158 & 40 \\
\hline 50 a 59 & 80 & 20 \\
\hline Mais de 59 & 19 & 5 \\
\hline Total & 400 & 100 \\
\hline
\end{tabular}

Houve predomínio de motoristas na faixa etária de 35 a 44 anos de idade (34\%).

Entre as queixas de saúde relatadas, constatou-se associação positiva com a faixa etária: dificuldades auditivas e de compreensão de fala ( $p=0,0006)$, cansaço e sono ( $p=$ o,oog9), e obesidade ( $p=0,0001)$.

A carga horária diária de trabalho (tempo de viagem) variou entre 3 e 24 horas, com uma média de 12,77 horas diárias. A distribuição do tempo de viajem ocorreu deu, na amostra, da seguinte maneira:
Tabela 2 - Número e proporção dos motoristas estudados, por faixas de trabalho, São Paulo, $2005(\mathrm{~N}=400)$

\begin{tabular}{l|c|c}
\hline Horas de Trabalho & $\mathrm{N}$ & $\%$ \\
\hline Até $7 \mathrm{~h}$ & 56 & 14 \\
\hline De $8 \mathrm{~h}$ a $10 \mathrm{~h}$ & 81 & 20 \\
\hline De $11 \mathrm{~h}$ a $13 \mathrm{~h}$ & 117 & 29 \\
\hline De $14 \mathrm{~h} \mathrm{a} 16 \mathrm{~h}$ & 75 & 19 \\
\hline Mais de $16 \mathrm{~h}$ & 71 & 18 \\
\hline Total & 400 & 100 \\
\hline
\end{tabular}

Nota-se, portanto, que a maioria $(68,3 \%)$ trabalha de 9 a 17 horas por dia.

$\mathrm{Na}$ análise das horas de trabalho em relação às queixas de saúde, constatou-se associação positiva com câimbras e tensão nos membros superiores ( $p$ = o,ooo4) e problemas emocionais - sentimentos negativos, depressão, angústia, ansiedade ( $\mathrm{p}=\mathrm{o}, \mathrm{Ooo} 2)$.

As horas de sono diárias variaram entre 2 e 12 horas, com predomínio do intervalo de 5 a 8 horas e uma média de 7 horas diárias de sono, apresentando a seguinte distribuição:

Tabela 3 - Número e proporção dos motoristas estudados por duração do sono, São Paulo, $2005(\mathrm{~N}=400)$

\begin{tabular}{l|c|c}
\hline Horas de sono & N & $\%$ \\
\hline o a 3 horas & 15 & 4 \\
\hline 4 a 5 horas & 83 & 21 \\
\hline 6 a 7 horas & 118 & 29 \\
\hline 8 a 9 horas & 154 & 38 \\
\hline 10 a 12 horas & 30 & 8 \\
\hline Total & 400 & 100 \\
\hline
\end{tabular}

Na análise da associação entre as horas de sono e os problemas de saúde relatados, constatou-se associação positiva com câimbras e tensão nos membros superiores ( $p$ = o,0002). Houve associação positiva entre os hábitos dos motoristas e as horas de sono, o uso de energéticos (p = o,ooo1) e o hábito de ingerir café puro $(\mathrm{p}=\mathrm{o}, 0061)$.

Quantos aos hábitos de consumo e comportamentos durante as viagens, que podem gerar impactos negativos sobre a saúde geral e sobre a saúde vocal, podem ser observados na tabela 4 . 
Tabela 4 - Freqüência de hábitos de consumo e comportamentos referidos pelos motoristas, São Paulo, 2005 $(\mathrm{N}=400)$

\begin{tabular}{l|c|c|c}
\hline Hábitos & Sempre (\%) & Às vezes (\%) & Nunca (\%) \\
\hline Viajar com os vidros abertos & 52,5 & 37,25 & 10,25 \\
\hline Viajar com o teto solar aberto & 31,25 & 29,5 & 39,25 \\
\hline Viajar com o ar condicionado ligado & 20,75 & 33,75 & 45,5 \\
\hline Ingestão de água constantemente & 49 & 45,25 & 5,75 \\
\hline Ingestão de café puro & 50 & 37,75 & 14,25 \\
\hline Alimentação gordurosa & 33,25 & 51,25 & 15,5 \\
\hline Ingestão de bebida alcoólica & 4 & 39,5 & 56,5 \\
\hline Tabagismo & 21,25 & 11,25 & 67,5 \\
\hline Consumo de energético & 1,25 & 18,25 & 80,5 \\
\hline Consumo de estimulantes ("rebites") & 0,25 & 7,25 & 92,5 \\
\hline Uso de drogas & 0 & 2 & 98 \\
\hline
\end{tabular}

Na análise da associação entre os hábitos dos motoristas e as queixas de saúde, observou-se associação positiva entre viajar com os vidros abertos e queixas de tosse constante $(p=o, 0049)$, tabagismo e tosse $(p=$ o,ooo1), tabagismo com sensação de garganta seca ( $\mathrm{p}$ = o,o276), tabagismo com cansaço ao falar ( $\mathrm{p}=\mathrm{o}, \mathrm{oo} 12)$.

Quanto às queixas e problemas de saúde que podem gerar impactos negativos ou comprometimentos da comunicação, como fator de qualidade de vida, foram encontrados:

Tabela 5 - Freqüência de queixas e problemas de saúde referidos pelos motoristas São Paulo, $2005(\mathrm{~N}=400)$

\begin{tabular}{l|c|c|c} 
Queixas e Problemas de saúde & Sempre (\%) & Às vezes (\%) & 51,25 \\
Problemas de postura & 16,5 & 31 & 33,25 \\
\hline Problemas de audição & 6,75 & 21,5 & 77 \\
\hline Tonturas & 1,5 & 66,5 & 30 \\
\hline Resfriados e gripes & 3,5 & 42,75 & 42,5 \\
\hline Problemas estomacais & 14,75 & 44,5 & 41,51 \\
\hline Estresse/depressão & 14 & 46 & 46,5 \\
\hline Tosse & 7,5 & 16,25 & 82 \\
\hline Sensação de bolo na garganta & 1,75 & 17 & 81,5 \\
\hline Cansaço ao falar & 1,5 & 26,5 & 69,25 \\
\hline Rouquidão & 4,25 & 9,75 & 63,5 \\
\hline Pigarro & 4,25 & 4,5 & \\
\hline Dor ou ardor na garganta & 4,5 & 40,75 & 54,75 \\
\hline Garganta seca & & & \\
\hline
\end{tabular}




\section{Discussão}

As relações entre idade e cansaço, sono e obesidade, associadas às longas jornadas de trabalho diário e ao consumo de energéticos e café, indicam redução gradativa da qualidade de vida, com impactos negativos na saúde física, mental, vocal e comunicativa dos motoristas (Mello e col., 200o).

As dificuldades auditivas e de compreensão de fala podem estar estreitamente relacionadas, com prejuízos para a comunicação, para as relações interpessoais, sociais e também profissionais dos motoristas, lembrando que muitos deles utilizam a comunicação por sistema de rádio-amador e celular durante o trabalho, o que demanda condições de audição saudável para compreender o que é dito, mesmo com o ruído interno na cabine do caminhão e o ruído externo do trânsito. Dificuldades comunicativas podem comprometer a troca de informações e a qualidade do trabalho realizado. Nota-se, pela tabela 5 , que cerca de $37 \%$ dos sujeitos têm problemas constantes de audição; entretanto a tabela 1 mostra que a faixa etária não justifica as dificuldades de audição, uma vez que a maioria dos sujeitos da pesquisa está na faixa entre 40 e 49 anos. Isso leva a pensar na possibilidade de que os problemas auditivos advenham de causas ocupacionais, uma vez que vários autores (Cordeiro e col., 1994; Santos Júnior e Mendes, 1999; Cepinho e col., 2003; Freitas e Nakamura, 2003; Mendes, 2003; Silviero e col., 2005) afirmam que os problemas auditivos, em motoristas, podem ter origem ocupacional em decorrência da exposição ao ruído, às vibrações dos veículos e a produtos químicos, e podem caracterizar-se como Perda Auditiva Induzida pelo Ruído (PAIR).

A tabela 2 mostra que a jornada de trabalho diária dos motoristas é longa, maior que 8 horas e comprometem o tempo de sono e o descanso, com implicações negativas na saúde física e mental, podendo gerar problemas musculares e posturais com sintomas como tensão, fadiga, câimbras e dores; o sono insuficiente e o cansaço podem predispor ao estresse emocional e à depressão e a sentimentos negativos, como a angústia e a ansiedade, os quais podem ter relação com distúrbios alimentares, repercutindo em obesidade e em problemas digestivos (tabelas 3, 4 e 5). Estudos anteriores (Silviero e col., 2005) identificaram problemas como falta de tempo para a alimentação como uma das causas de distúrbios gastrintestinais e sintomas e doenças relacionadas ao sistema músculo-esquelético como a principal causa de morbidade em motoristas.

Segundo Behlau e Pontes (1999), alimentos pesados, gordurosos e condimentados lentificam a digestão e dificultam a livre movimentação do músculo diafragma, essencial para a respiração e apoio para a produção da voz, além de provocar refluxo gastroesofágico. A alimentação gordurosa e a obesidade também conferem risco à saúde por estarem relacionada a quadros hipertensivos e doenças cardíacas (Netterstrom e Juel, 1988; Neri Soares e Soares, 2005).

Diversos autores (Pinho, 1997; Behlau e Pontes, 1999; Oliveira, 2004) apontam relações entre falta de repouso adequado e problemas posturais, tensões corporais, alimentação inadequada, refluxo gastroesofágico, resfriados e/ou gripes e problemas de voz - irritações, edemas e a alterações laríngeas e vocais -, juntamente com a restrição da expressividade corporal e da qualidade vocal na comunicação.

Quanto aos hábitos de consumo e comportamentos (tabela 4), o café, os energéticos e o rebite são substâncias ingeridas com a finalidade de combater o sono e o cansaço e manter o sujeito acordado por mais tempo. Alguns motoristas, pressionados pela necessidade de cumprir prazos de entrega de cargas, acabam fazendo uso desses produtos para evitar as necessárias paradas para o sono e descanso.

A cafeína é uma substância neuroestimulante que pode causar ressecamento da mucosa do trato vocal, refluxo gastroesofágico, irritações laríngeas e alterações na qualidade vocal, além de tremor associado a tiques vocais e velocidade de fala acelerada, dificultando a compreensão (Behlau e Pontes, 1999; Oliveira, 2004; Braga e col., 2007). 0 uso de energéticos ou de rebite não é mencionado na literatura fonoaudiológica sobre saúde vocal, mas levando-se em conta que o rebite é uma droga neuroestimulante, que tem em sua composição substâncias como anfetaminas, que são psicotróficos estimulantes que causam dependência física e psíquica, e podem causar ressecamento da mucosa do trato vocal e tremor associado a tiques vocais e velocidade de fala acelerada, dificultando a compreensão (Braga e col., 2007), além de reações como agressividade, excitação, euforia, hiperatividade, insônia, hipertensão, falta de apetite, emagrecimento, alucinações, delírios, aumento de temperatura corporal, convulsão e até mesmo a morte (Fereira e Fraga, 2005). 
O hábito de viajar com os vidros e o teto solar abertos expõe o sujeito ao vento e à friagem dele decorrente, bem como à poeira, à fumaça, à fuligem de queimadas e à poluição, agentes químicos de riscos ambientais ocupacionais que agridem o sistema respiratório - nariz, boca, garganta, laringe e pulmões (Miranda e col., 2005; Penteado e col., 2005). A exposição diária e crônica ao ar poluído pode resultar em uma resposta irritativa respiratória e do trato vocal, sendo que os sintomas vocais e laríngeos relacionados à poluição geralmente incluem rouquidão, tosse, sensação de irritação e secura na garganta, dificuldade respiratória e irritação dos tecidos e mucosas de nariz, bocal, olhos e trato vocal e respiratório, que afetam a voz (Behlau e Pontes, 1999). No tocante à friagem (tanto a advinda dos ventos dos vidros e do teto solar abertos, como a proveniente do uso do aparelho de ar condicionado), vale lembrar que as mudanças bruscas de temperatura e choques térmicos podem causar problemas de saúde geral como gripes, resfriados, inflamações e infecções de laringe, comprometendo a saúde vocal (Behlau e Pontes, 1999; Miranda e col., 2005; Penteado e col., 2005).

No que diz respeito ao tabagismo, se sabe que a fumaça do cigarro causa irritação, inflamação e edema da mucosa laríngea, ocasionando agravamento da voz, cansaço ao falar ou cantar, dificuldade de projeção da voz, incoordenação pneumofônica, pigarro, tosse, doenças cardíacas, e câncer de laringe e de pulmão (Netterstrom e Juel, 1988; Pinho, 1997; Oliveira, 2004; Miranda e col., 2005; Penteado e col., 2005).

O hábito de ingerir água é considerado saudável para a produção da voz, uma vez que ingestão de líquidos favorece a hidratação da laringe e do trato vocal, evitando também as sensações de garganta e boca secas. É desejável a ingestão de, em média, dois litros de água diariamente (Behlau e Pontes, 1999).

Além dos riscos para a segurança e saúde geral dos motoristas, o consumo de bebidas alcoólicas, principalmente as destiladas, acarreta o ressecamento e a irritação da mucosa da laringe, causando disfonia crônica (Pinho, 1997; Oliveira, 2004).

Nota-se, portanto, que as condições de trabalho dos motoristas têm impactos negativos sobre a sua qualidade de vida e diversos aspectos da saúde geral, com repercussões possíveis na sua saúde vocal e comunicação.

\section{Conclusões}

O estudo levantou diversos aspectos das condições de trabalho de motoristas de caminhão que podem exercer impactos negativos sobre a saúde geral, com prejuízos para a comunicação e para a qualidade de vida desses trabalhadores.

Há necessidade de desenvolvimento de ações educativas para a promoção da saúde desses trabalhadores que sejam orientadas por uma perspectiva ampla e abrangente de saúde e relacionadas às condições e organização do trabalho e à qualidade de vida - incluindo a comunicação. As ações devem envolver os motoristas e as empresas de transporte que os contratam, além de empresas relacionadas aos ramos de logística, transportes e estradas de rodagem, em parcerias pautadas pela integralidade, interdisciplinaridade e intersetorialidade, articulando as áreas de Saúde do Trabalhador, Fonoaudiologia, Psicologia, Nutrição, Fisioterapia, Medicina e outras.

Vale ressaltar que outros estudos se fazem pertinentes para o aprofundamento da investigação das condições e da organização do trabalho de motoristas de caminhão e de como elas interferem nos espaços de vida extra-trabalho, além das relações dessas com aspectos de subjetividade, por exemplo, as percepções, os receios, as satisfações e as expectativas dos motoristas sobre as relações entre saúde, trabalho e qualidade de vida e, também, sobre ações possíveis de serem implementadas para a transformação das condições de trabalho e a melhoria da sua atividade profissional.

\section{Anexo - Questionário}

Motorista de caminhão e carreteiro, complete os espaços e assinale com $\mathrm{X}$ no quadradinho referente às coisas e situações que acontecem com você:

Iniciais do nome: Idade: anos

Sexo: $\square$ Masc. $\square$ Fem.

Motorista: $\square$ Autônomo $\square$ Empregado

Tipo/Modelo do caminhão:

Tipo de carga:

Tipo de Rota: $\square$ Curta $\square$ Longa

Trabalha em média _____ horas por dia.

Dorme em média _______ horas por dia. 


\section{O que você acha da sua voz e da sua fala?}

Gosto do som da minha voz

Gosto "mais ou menos" do som da minha voz

Não gosto do som da minha voz

Minha voz é muito grossa

Minha voz muito fina

O som da minha voz é adequando / normal

0 volume da minha voz é muito forte

O volume da minha voz é muito fraco

O volume da minha voz é adequado / normal

Minha fala é muito rápida

Minha fala é muito lenta e devagar

Acho que a velocidade da minha fala é adequada /normal

Eu troco sons na fala (troca "letras" quando fala)

2. Sua voz é importante no seu trabalho?
Sim
$\square$ Não
Às vezes

3. Como você usa a voz no trabalho de motorista?

Fala levantando peso ou fazendo força para carregar o caminhão

$\square$ Sempre $\square$ Nunca $\square$ Às vezes

Grita com o "chapa" enquanto carrega o caminhão

$\square$ Sempre $\square$ Nunca $\square$ Às vezes

Conversa com o "chapa" na cabine durante a viagem

$\square$ Sempre $\square$ Nunca $\square$ Às vezes

Fala ao Rádio Amador

$\square$ Sempre $\quad \square$ Nunca $\square$ Às vezes

Fala ao telefone celular e/ou viva-voz

$\square$ Sempre $\square$ Nunca $\square$ Às vezes

Canta acompanhando músicas do rádio (AM/FM ou CD)

$\square$ Sempre $\quad \square$ Nunca $\quad \square$ Às vezes

Canta sozinho

$\square$ Sempre $\square$ Nunca $\square$ Às vezes

Grita com pessoas na rua e no trânsito

$\square$ Sempre $\square$ Nunca $\square$ Às vezes

Conversa com cobradores de pedágio
Sempre
Nunca
$\square$ Às vezes

Viaja em silêncio o tempo todo

$\square$ Sempre $\square$ Nunca $\square$ Às vezes
Nas paradas conversa com clientes/funcionários dos postos

$\square$ Sempre $\square$ Nunca $\square$ Às vezes

Nas paradas, telefona para familiares, amigos e amigas

$\square$ Sempre $\square$ Nunca $\square$ Às vezes

4. A sua voz é importante na sua vida pessoal?

$\square \operatorname{Sim} \quad \square$ Não $\quad \square$ Às vezes

\section{Como você usa a voz na sua vida pessoal?}

Conversa com a família

$\square$ Sempre $\square$ Nunca $\square$ Às vezes

Conversa com os amigos

$\square$ Sempre $\quad \square$ Nunca $\square$ Às vezes

Conversa com namorado ou namorada

$\square$ Sempre $\square$ Nunca $\square$ Às vezes

Conversa para fazer negócios

$\square$ Sempre $\square$ Nunca $\square$ Às vezes

Canta, faz leituras ou testemunhos na Igreja

$\square$ Sempre $\square$ Nunca $\square$ Às vezes

Canta em casa, no chuveiro ou acompanhando as músicas que tocam no aparelho de rádio, de CD ou no "videokê"

$\square$ Sempre $\square$ Nunca $\square$ Às vezes

Canta em rodas de amigos, churrascos, festas e bares

$\square$ Sempre $\square$ Nunca $\square$ Às vezes

\section{Quais os hábitos que você tem?}

Viaja com os vidros da cabine abertos

$\square$ Sempre $\square$ Nunca $\square$ Às vezes

Viaja com o teto solar da cabine aberto
$\square$ Sempre
Nunca
$\square$ Às vezes

Viaja com ar condicionado ligado

$\square$ Sempre $\square$ Nunca $\square$ Às vezes

Fuma

$\square$ Sempre $\square$ Nunca $\square$ Às vezes

Toma bebida alcóolica

$\square$ Sempre $\quad \square$ Nunca $\square$ Às vezes

Toma energéticos

$\square$ Sempre $\quad \square$ Nunca $\square$ Às vezes

Toma rebite

$\square$ Sempre $\square$ Nunca $\square$ Às vezes 
Usa drogas (cocaína, maconha, crack e outros)

$\square$ Sempre $\square$ Nunca $\square$ Às vezes

Chupa pastilhas para a garganta

$\square$ Sempre $\square$ Nunca $\square$ Às vezes

Come alimentos gordurosos, frituras ou apimentados

$\square$ Sempre $\square$ Nunca $\square$ Às vezes

Toma café puro

$\square$ Sempre $\square$ Nunca $\square$ Às vezes

Bebe água

$\square$ Nunca $\square$ de 1 a 7 copos por dia

8 copos ou mais por dia.

7. Quais os problemas de saúde que você tem?

Dor de cabeça

$\square$ Sempre $\quad \square$ Nunca $\quad \square$ Às vezes

Cãimbras, tensão e/ou dor nos ombros, braços e mãos

$\square$ Sempre $\square$ Nunca $\square$ Às vezes

Cãimbras, tensão e/ou dor na nuca e/ou no pescoço
Sempre
Nunca
Às vezes

Range os dentes

$\square$ Sempre $\square$ Nunca $\square$ Às vezes

Dor na ATM (articulação temporo-mandibular)

Sempre $\square$ Nunca $\square$ Às vezes

Problemas de postura, de coluna e/ou dor nas costas

Sempre $\square$ Nunca $\square$ Às vezes

Perda da audição ou dificuldade para entender conversas ao telefone ou em ambientes de festas e com ruído

Sempre $\square$ Nunca $\square$ Às vezes

Apito ou zumbido no ouvido

$\square$ Sempre $\square$ Nunca $\square$ Às vezes

Otite, inflamação ou dor de ouvido

$\square$ Sempre $\square$ Nunca $\square$ Às vezes

Tonturas, náuseas e vômitos

$\square$ Sempre $\square$ Nunca $\square$ Às vezes

Resfriados e gripes
Sempre $\square$ Nunca
Às vezes

Nariz ressecado ou escorrendo, alergia, coceira ou sangramento no nariz, rinite, sinusite, bronquite, asma)
Sempre
Nunca
Às vezes

Azia, "queimação" no estômago, gastrite ou refluxo

$\square$ Sempre $\square$ Nunca $\square$ Às vezes

Sentimentos negativos de estresse, nervoso, depressão, insegurança, angústia, medo e ansiedade

$\square$ Sempre $\square$ Nunca $\square$ Às vezes

Machucados, placas brancas ou feridas na boca (lábios, língua, bochechas ou céu da boca)

$\square$ Sempre $\square$ Nunca $\square$ Às vezes

Insônia (falta de sono e problemas para dormir)

$\square$ Sempre $\square$ Nunca $\square$ Às vezes

Cansaço e sono

$\square$ Sempre $\square$ Nunca $\square$ Às vezes

Ronco

$\square$ Sempre $\square$ Nunca $\square$ Às vezes

Problemas dentários (cáries, perda ou falta de dentes, dentes tortos, dentes quebrados e uso de dentaduras)

Obesidade (gordo, acima do peso ideal)

Problemas de coração, hipertensão, taquicardia ou "batedeira"

Diabetes

$\square$ Problemas de circulação, varizes ou peso e cansaço na perna

\section{Você tem queixas, sintomas e problemas na voz?}

Rouquidão (voz rouca)

$\square$ Sempre $\square$ Nunca $\square$ Às vezes

Pigarro

$\square$ Sempre $\square$ Nunca $\square$ Às vezes

Tosse

$\square$ Sempre $\square$ Nunca $\square$ Às vezes

Perda da voz (sem som nenhum - afonia - mutismo)

$\square$ Sempre $\square$ Nunca $\square$ Às vezes

Garganta seca, raspando, coceira ou "areia" na garganta

$\square$ Sempre $\square$ Nunca $\square$ Às vezes

Dor ou ardor na garganta

$\square$ Sempre $\quad \square$ Nunca $\square$ Às vezes

Falta de ar ao falar

$\square$ Sempre $\square$ Nunca $\square$ Às vezes 
Cansaço ao falar

$\square$ Sempre $\square$ Nunca $\square$ Às vezes

A voz falha ou quebra ao falar

$\square$ Sempre $\square$ Nunca $\square$ Às vezes

Desconforto ou dor ao falar

Sempre $\square$ Nunca $\square$ Às vezes

Sensação de "bolo" na garganta

$\square$ Sempre $\square$ Nunca $\square$ Às vezes

Dificuldades para engolir ou dor para engolir
Sempre
$\square$ Nunca
$\square$ Às vezes

A voz falha ou quebra ao cantar (a voz quebra ou some em algumas notas)

$\square$ Sempre $\square$ Nunca $\square$ Às vezes

Desconforto ou dor ao cantar
Sempre
Nunca
Às vezes

\section{0 que afeta a sua voz e sua 'garganta'?}

Falar muito

Falar alto

Gritar

Cantar

Poeira

Fumaça

Fuligem de queimada de cana

Vento, friagem ou mudança de clima e temperatura

Ar condicionado

Fumo

Alimentos gelados ou bebidas geladas

Álcool

Drogas

Cheiros fortes e produtos químicos

Frituras, alimentos apimentados, pesados e gordurosos

Estresse, nervoso, ansiedade ou emoções fortes

Café

Refrigerantes e bebidas com gás

Energéticos

Outros:

10. Já fez algum tratamento para a voz?

$\square \operatorname{Sim} \quad \square$ Não

II. Conhece o trabalho da fonoaudiologia?

Sim $\square$ Não

\section{Referências}

ALVES, R. B. Vigilância em saúde do trabalhador e promoção da saúde: aproximações possíveis e desafios. Cadernos de Saúde Pública, Rio de Janeiro, v. 19, n. 1, p. 319-322, 2003.

BEHLAU, M.; PONTES, P. Higiene vocal: cuidando da voz. Rio de Janeiro: Revinter, 1999.

BRAGA, N. A. et al. Efeitos dos medicamentos na qualidade vocal e na laringe. In: PINHO, S. M. R.

Temas em voz profissional. Rio de Janeiro: Revinter, 2007. p. 185-201.

BRASIL. Ministério de Trabalho e Emprego.

Classificação brasileira de ocupações. Brasília, DF, [s.d.]. Disponível em: <http://www.mtecbo.gov.

$\mathrm{br} / \mathrm{busca} /$ descricao.asp? codigo=7825>. Acesso em: 20 abr. 2005 .

CEPINHO, P. C.; CORREA, A.; BERNARDI, A. P. A. Ocorrência de perda auditiva em motoristas de ônibus e caminhões de São Paulo. Revista Cefac, São Paulo, v. 5 n. 2, p. 181-186, 2003.

CORDEIRO, R.; LIMA FILHO, E. C.; NASCIMENTO, L. C. R. Associação da PAIR com o tempo acumulado de trabalho entre motoristas e cobradores. Cadernos de Saúde Pública, Rio de Janeiro, v. 10, n. 2, p. 210-221, 1994

CORRÊA FILHO, R. H. et al. Perda auditiva induzida por ruído e hipertensão em condutores de ônibus. Revista de Saúde Pública, São Paulo, v. 36, n. 6, p. 693-701, 2002.

COSTA, D. D.; MIRANDA, J. S.; PENTEADO, R. Z. Investigação dos usos da voz por motoristas de caminhão. Revista da Sociedade Brasileira de Fonoaudiologia, Santos, p. 168, 2005. Suplemento especial

FERREIRA, A.; FRAGA, A. Carreta dos sonhos. Revista Painel, Piracicaba, n. 46, 2005. Disponível em: <http://www.unimep.br/fc/painelonline/>. Acesso em: 22 maio 2007.

FLECK, M. Aplicação da versão em português do instrumento de avaliação de qualidade de vida da Organização Mundial da saúde (WHOQOL-10o). Revista de Saúde Pública, São Paulo, v. 33, n. 2, p. 198-205, 1999. 
FLECK, M. P. A. et al. Aplicação da versão em português do instrumento abreviado de avaliação da qualidade de vida "WHOQOL/Bref". Revista de Saúde Pública, São Paulo, v. 34, n. 2, p. 178-183, 2000.

FREITAS, R. G. F.; NAKAMURA, H. Perda auditiva por ruído em motoristas de ônibus com motor dianteiro. Saúde em Revista, Piracicaba, v. 10, n. 5, p. 13-19, 2003.

GONÇALVES, C. G. O.; PENTEADO, R. Z.; SILVÉRIO, K. C. A fonoaudiologia e saúde do trabalhador: a questão da saúde vocal do professor. Saúde em Revista, Piracicaba, v. 7, p. 46-51, 2005.

MELLO, M. T. et al. Sleep patterns and sleep-related complaints of Brazilian interstate bus drivers.

Brazilian Journal Medical Biological Research, Ribeirão Preto, v. 33, p. 71-77, 2000.

MENDES, R. Patologia do trabalho. São Paulo: Atheneu, 2003.

MIRANDA, J. S.; COSTA, D. D.; PENTEADO, R. Z. Percepções sobre a voz/saúde vocal por motoristas de caminhão. Revista da Sociedade Brasileira de Fonoaudiologia, Santos, p. 170, 2005. Suplemento especial.

MONTOVANI, J.; WEBER, S. Doenças do sono associadas a acidentes com veículos automotores: revisão das leis e regulamentações para motoristas. Revista Brasileira de Otorrinolaringologia, São Paulo, v. 68, n. 3, p. 412-415, 2002.

NERI SOARES, W. L.; SOARES, C. Condições de saúde no setor de transporte rodoviário de cargas e de passageiros: um estudo baseado na Pesquisa Nacional por Amostra de Domicílios. Cadernos de Saúde Pública, Rio de Janeiro, v. 21, n. 4, p. 1107-1123, 2005 .

NETTERSTROM, B.; JUEL, K. Impact of work-related and psychosocial factors on the development of ischemic heart disease among urban bus drivers in Denmark. Scandinavian Journal of Work, Environmental and Health, Copenhagen, v. 14, p. 231$238,1988$.

OLIVEIRA, C. G. Pensando a fonoaudiologia em saúde coletiva. In: LACERDA, C. B. F.; PANHOCA, I. (Org.). Tempo de fonoaudiologia II. Taubaté: Cabral, 1998. p. 29-38.
OLIVEIRA, I. B. Avaliação fonoaudiológica da voz: reflexões sobre condutas com enfoques à voz profissional. In: FERREIRA, L. P. (Org.). Tratado de fonoaudiologia. São Paulo: Roca, 2004. p. 11-23.

PENTEADO, R. Z. Voz e qualidade de vida. Revista da Sociedade Brasileira de Fonoaudiologia, Foz do Iguaçu, 2004. Edição especial. 1 CD-ROM.

PENTEADO, R. Z. Voz e saúde do trabalhador. Revista da Sociedade Brasileira, Salvador, 2006. Edição especial. 1 CD-ROM.

PENTEADO, R. Z.; COSTA, D. D.; MIRANDA, J. S. Aspectos intervenientes na qualidade e saúde vocal: as percepções de motoristas de caminhão. Revista da Sociedade Brasileira de Fonoaudiologia, Santos, p. 171, 2005. Suplemento especial.

PINHO, S. Manual de higiene vocal para profissionais da voz. Carapicuíba: Pró Fono, 1997.

RAMÍREZ, M. L. C. Calidad de vida y promoción de la salud. In: RESTREPO, H. E.; MÁLAGA, H. Promoción de la salud: como construir vida saludable. Bogotá: Ed. Médica Panamericana, 2001. p. 56-64.

SANTOS JÚNIOR, E. A.; MENDES, R. Estudo das condições de trabalho e saúde de motoristas de ônibus urbanos de Belo Horizonte - MG. Revista Brasileira de Saúde Ocupacional, São Paulo, v. 95/96, n. 25, p. 131-142, 1999.

SILVA, L. F.; MENDES, R. Exposição combinada entre ruído e vibração e seus efeitos sobre a audição de trabalhadores. Revista de Saúde Pública, São Paulo, v. 39, n. 1, p. 9-17, 2005.

SIVIERO, A. B. et al. Prevalência de perda auditiva em motoristas de ônibus do transporte coletivo da cidade de Maringá-PR. Revista Cefac, São Paulo, v. 7, n. 3, p. 376-381, 2005.

Recebido em: 20/08/2007

Reapresentado em: 15/05/2008

Aprovado em: 18/06/2008 